\title{
Efficacy of platelet rich plasma injection in treatment of plantar fasciitis
}

\author{
Rahul Kadam, Sukant Vijay*, Abhay Chhallani, Santosh Pandhare, \\ Abhishek Gupta, Ritesh Sawant Singh
}

Department of Orthopaedics, MGM Medical College, Navi Mumbai, India

Received: 02 March 2017

Revised: 28 March 2017

Accepted: 04 April 2017

\author{
*Correspondence: \\ Dr. Sukant Vijay, \\ E-mail: vijay.sukant@gmail.com
}

Copyright: (c) the author(s), publisher and licensee Medip Academy. This is an open-access article distributed under the terms of the Creative Commons Attribution Non-Commercial License, which permits unrestricted non-commercial use, distribution, and reproduction in any medium, provided the original work is properly cited.

\begin{abstract}
Background: Platelet rich plasma is a recently introduced therapy for treatment of chronic painful conditions in orthopaedics, it acts mainly by promoting healing process. PRP has an increased concentration of platelets which initiate tissue repair by releasing growth factors. Increased concentrations of autologous platelets yield high concentrations of growth factors, subsequently leading to intensified healing of soft tissue on a cellular level. This study was conducted to evaluate the efficacy of platelet rich plasma injection in treatment of plantar fasciitis.

Methods: This study was conducted on the patients coming to orthopaedic OPD at MGM medical college and hospital, kamothe, Navi Mumbai. Total of 40 planter fasciitis cases were taken in this study. Out these 40 patients 23 were Male and 17 were female. The mean age 45.85 (range 25-75). Patients were followed up for 3 months with regular interval and at each visit vas score was evaluated and noted.Total duration of study was 3 months from October 2016 to December 2016.

Results: The mean pre injection vas score was 7.15 (Male -7.13 , Female -6.70 ). The mean vas score at time of follow up after one week was 6.20 (Male - 6.22 Female - 6.18). The mean vas score at time of follow up after 6 week was 5.62 (Male - 5.66 Female - 5.70). The mean vas score at time of follow up after 3 months was 3.20 (Male - 3.13 Female - 3.29).

Conclusions: PRP in plantar fasciitis shows promising short term results providing patients with gradual sustained pain relief, improving daily function and lifestyle activity level. However long term results needs to be evaluated.
\end{abstract}

Keywords: PRP, Plantar Fasciitis, Vas score

\section{INTRODUCTION}

Platelet rich plasma (PRP) is autologous blood derivative with enhanced platelet concentration which basically has properties of biologically enhancing the healing process naturally. ${ }^{1}$ Plasma with such higher concentration of platelets on activation leads to release of various growth factors which in turn augment tissue repair and jump start the healing process. ${ }^{1}$

PRP with $1,000,000$ platelets/ $\mu$ l has shown scientific proof of enhancement of bone and soft tissue healing.
Hence $1,000,000 / \mu 1$ concentration of platelet in a $5 \mathrm{ml}$ volume of plasma is the working definition of PRP. ${ }^{1}$

Composition of PRP varies from patient to patient as it is autologous and it may also vary with the device used for preparation, methodology, storage technique and many other factors ${ }^{2}$ Due to this reason the response may also be different in different individual. ${ }^{2}$ This PRP needs to be activated before use. ${ }^{2}$ PRP is activated by thrombin (autologous or from animals), Calcium Chloride and procoagulant enzyme. ${ }^{2}$ PRP solutions injected directly for topical treatments are activated by local thrombin. ${ }^{2}$ Immediately after activation platelets start releasing 
various growth factors. ${ }^{2}$ These factors after secretion are involved in key process of tissue repair and cell proliferation cellular differentiation and extracellular matrix synthesis. 3,4

PRP activation is required prior to injection. ${ }^{5}$ Exogenous activation of PRP can occur by thrombin, calcium chloride or mechanical trauma. ${ }^{5}$ For activation PRP: Thrombin of 9:1 (OR) PRP: Calcium chloride (10\%) of 10:1 used. $^{5}$ Collagen is a natural activator of PRP, thus when PRP is used in soft tissue, it may not require exogenous activation. ${ }^{6}$

Plantar fasciitis affects general population working all day long standing on their feet as well as seasoned atheletes. Chronic plantar fasciitis is a common cause of foot complaints. The incidence of plantar fasciitis peaks in people between the ages of 40 to 60 years with no bias towards either sex. ${ }^{8}$ The thick connective tissue supporting the arch of plantar aspect of foot shows signs of inflammation. ${ }^{9}$ The reason for inflammation is repeated trauma from overuse or injury. In platar fasciitis there is underlying dengenration occuring near the site of origin of the plantar fascia at the medial tuberosity of the calcaneum. $^{9}$

Plantar fasciitis in acute stage is characterized by classical signs of inflammation including pain, swelling and loss of function, but in chronic cases histology shows no signs of inflammatory cell invasion into the affected area. ${ }^{10}$ The tissue instead is characterized by infiltration with macrophages, lymphocytes, and plasma cells; tissue destruction; and repair involving immature vascularization and fibrosis. ${ }^{10}$ The normal fascia tissue is replaced by an angiofibroblastic hyperplastic tissue which spreads itself throughout the surrounding tissue creating a self-perpetuating cycle of degeneration. ${ }^{10}$

Numerous methods have been advocated for treating plantar fasciitis, including rest, nonsteroidal antiinflammatory medication, night splints, foot orthosis, stretching protocols and extracorporeal shock wave therapy. ${ }^{11}$ Steroid injections are a popular method of treating the condition but only seem to be useful in the short term and only to a small degree. ${ }^{11}$ Other various types of surgical procedures have also been recommended. ${ }^{12-14}$ The use of corticosteroids is particularly troubling as several studies have linked plantar fascia rupture to repeated local injections of a corticosteroid. ${ }^{15,16}$ In an animal model the addition of growth factors to the ruptured tendon has been shown to increase the healing of the tendon. ${ }^{17}$ In humans it has been shown that the injection of whole blood into the tendon decreases the pain. ${ }^{18}$

\section{METHODS}

This study was conducted on the patients coming to orthopaedic OPD at MGM medical college ant hospital, kamothe, navi Mumbai. Total of 40 plantar fasciitis cases were included in this study. Total duration of study was 3 months from October 2016 to December 2016.

All affected patients were screened with X-ray of the bilateral calcaneum lateral views for bony abnormalities and to diffrentiate from subtalar arthritis.

Inclusion criteria were patients aged > 18 years, plantar fasciitis (6-12 months duration), Failed conservative treatment, who are able to understand the informed consent and patients with VAS pain score in the morning by first steps higher as 5 (0-10 scale).

Exclusion criteria were patients who have relief with medication and physical therapy, previouly operated for plantar fasciitis, inability to fulfill follow-up criteria, anemia (hemoglobin < 5.0), significant cardiovascular, renal or hepatic disease, pregnancy, (local) malignancy, systemic comorbidities of vascular insufficiency or neuropathy related to heel pain, hypothyroidism and diabetis.

\section{Pre injection data}

Complete data of the patient including name, age, sex, VAS score, side affected was collected before injection. Signed Informed Consent was taken from the participants.

\section{Post injection data}

After injection data related to complications, pain (assessment by using VAS Score), indications of fever, high grade pain, vomiting, any allergic reactions were noted. If require patients are hospitalized.

\section{Injection technique}

Initially, lignocaine is infiltrated into the skin and subcutaneous tissue as a local block. $0.5 \mathrm{ml}$ Calcium chloride $(10 \%)$ is mixed with $5 \mathrm{ml}$ of PRP for activation. Then $5 \mathrm{ml}$ platelets concentrate is injected using a $22-\mathrm{g}$ needle into the plantar fasciitis using a peppering technique. This technique involved a single skin portal and then fanning into multiple directions in fascia.

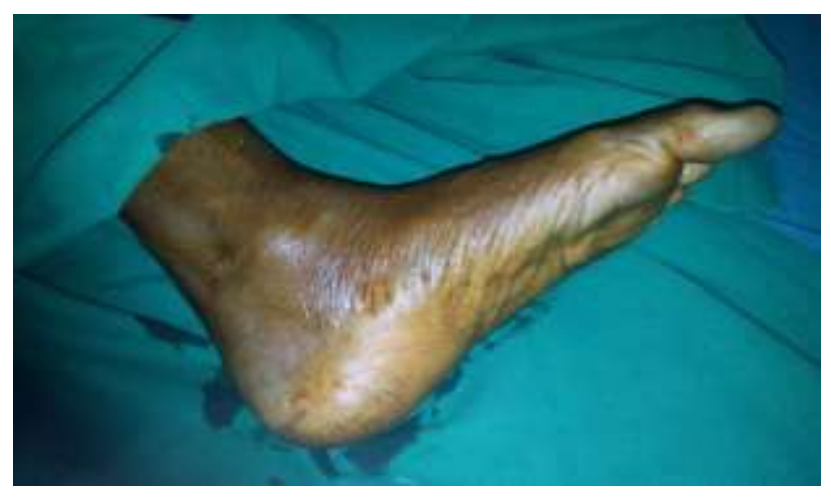

Figure 1: Pre injection scrubbing. 


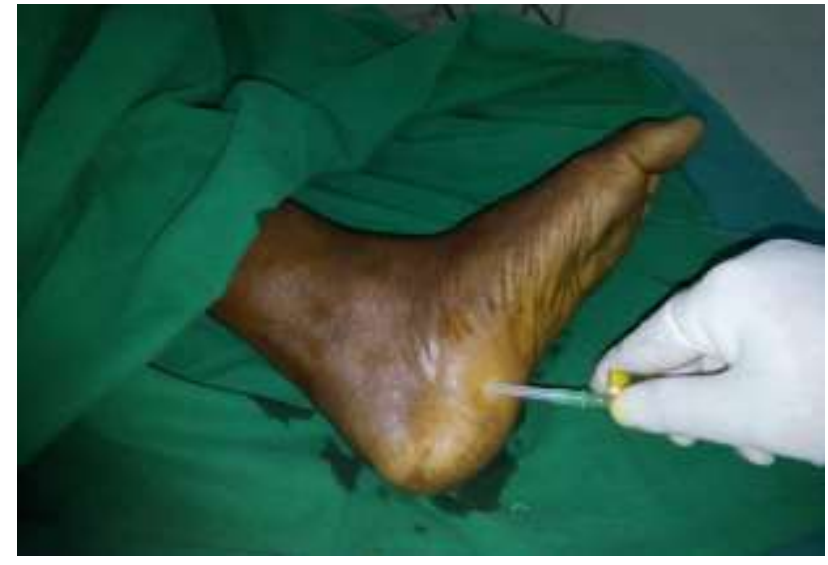

Figure 2: Point of maximal tenderness.

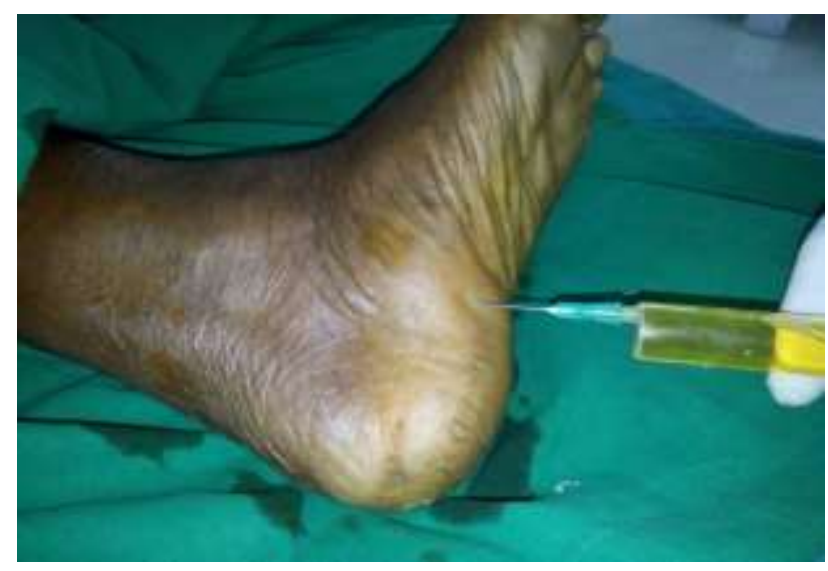

Figure 3: Technique of administering PRP injection.

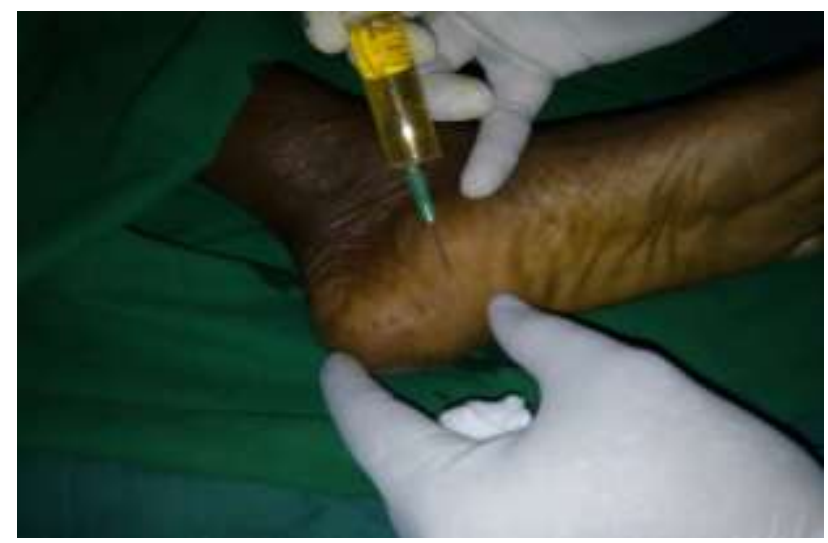

Figure 4: Peppering technique.

\section{Post-procedure protocol}

Immediately after the injection, the patient is kept in sitting position without moving the foot for 15 minutes. Patients will go to the physiotherapist to obtain stretching exercises. Patients are sent home with instructions to limit their use of the feet for approximately 48 hours. After 48 hours, patients are given a standardized stretching protocol to follow for 2 weeks. A formal strengthening program is initiated after this stretching.
No stressful activities were done until no rest pain, minimal tenderness and return of full motion

\section{Follow up evaluation}

Patients were evaluated for efficacy of treatment in terms of pain relief over a period of 3 months (one week, at 6 weeks and at 3 months). VAS score was used to access severity of pain.
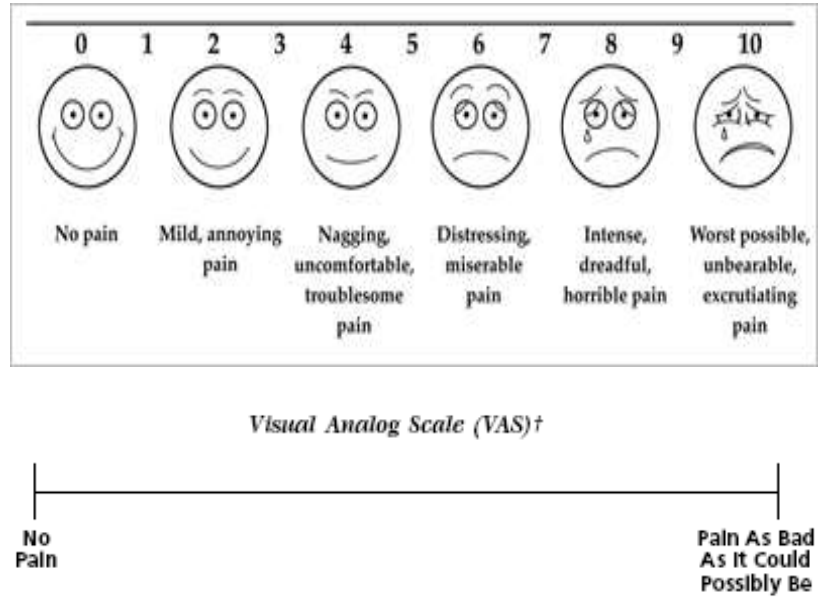

Figure 5: Visual analogue scale.

\section{Statistical analysis}

The results were tabulated and analysed. The statistical analysis was conducted using Microsoft excel 2010.

\section{RESULTS}

This study included total of 40 cases suffering from plantar fasciitis. The mean age of the patients was 45.85 (range 25-75). Out of 40 cases there were 16 bilateral cases and 8 unilateral cases. There were 23 male and 17 female cases. Patients were assessed by pain level as per vas scale pre injection, post injection one week, post injection 6 weeks and post injection 3 months. The mean pre injection vas score was 7.15 (Male -7.13, Female 6.70). The mean vas score at time of follow up after one week was 6.20 (Male -6.22 Female -6.18). The mean vas score at time of follow up after 6 week was 5.62 (Male 5.66; Female -5.70). The mean vas score at time of follow up after 3 months was 3.20 (Male -3.13 female 3.29).

Table 1: Demographic data of the patients.

\begin{tabular}{|lllll|} 
Sex & $\begin{array}{l}\text { No. of } \\
\text { patients }\end{array}$ & $\begin{array}{l}\text { Mean } \\
\text { age }\end{array}$ & $\begin{array}{l}\text { Mean } \\
\text { VAS score } \\
\text { (pre- } \\
\text { injection) }\end{array}$ & $\begin{array}{l}\text { Mean } \\
\text { VAS score } \\
\text { (post- } \\
\text { injection) }\end{array}$ \\
\hline Male & 23 & 50.17 & 7.13 & 3.13 \\
\hline Female & 17 & 40 & 6.70 & 3.29 \\
\hline Total & 40 & 45.85 & 7.15 & 3.20 \\
\hline
\end{tabular}




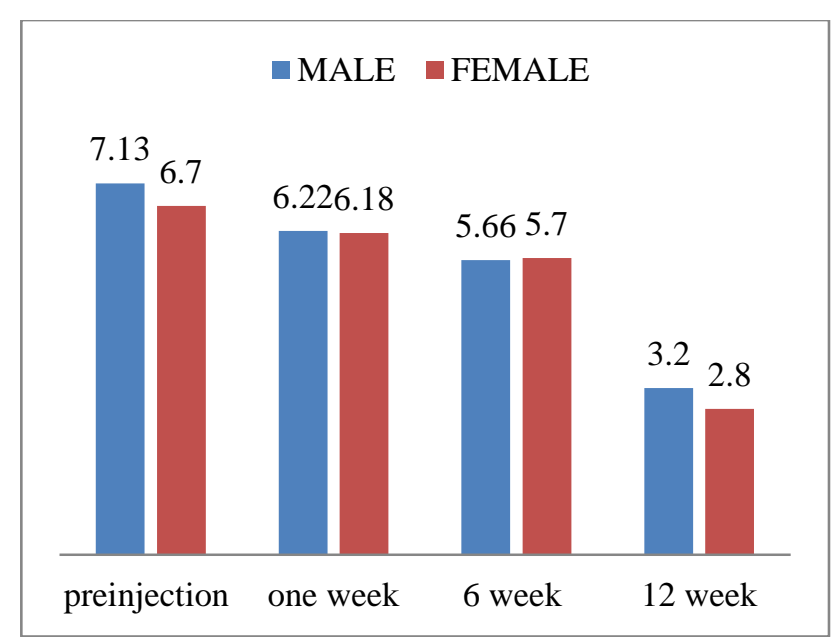

Figure 6: Depiction of VAS score pre injection and at different follow ups.

\section{DISCUSSION}

Scientific research and technology has provided new insight in understanding the biological potential of platelet in wound healing process. Platelet rich plasma (PRP) preparations have been used both in surgical and outpatient procedures in the treatment of several muscoloskeletal problems with effective results. PRP is increasingly used in treatment of chronic non-healing tendon injuries including the elbow, patella, and the achilles among others. The application of platelet rich plasma during arthroscopic rotator cuff repair is safe and effective, and produces results which seem to be stable with time.

Monto in his Level I, prospective randomized comparative series found that platelet-rich plasma injection was more effective and durable than corticosteroid injection. ${ }^{20}$

Nicolo Martinelli et al conducted a single-centre, uncontrolled, prospective, preliminary study, results of which indicated that treating chronic plantar fasciitis with PRP injections is safe and has the potential to reduce pain. ${ }^{21}$

Peerbooms et al postulate that the concentrated growth factors work in a synergetic manner to initiate a tendon healing response. This hypothesis is supported by in vitro research in the literature. Transforming growth factor $\beta 1$ is shown to significantly increase type I collagen production by tendon sheath fibroblasts. This same mechanism is likely to be active in chronic plantar fasciitis. $^{22}$

Baravarian et al say PRP is an effective non-invasive treatment that can obviate further surgery for plantar fasciitis. $^{23}$
Kumar et al in their study showed promising results in treatment of intractable planter fasciitis with platelet-rich plasma injection. $^{24}$

Wilson et al conducted prospective case series to report patient rated pain and disability following PRP injection in patient with chronic plantar fasciitis. They concluded that PRP is considered a safe therapeutic option with the ability to decrease heel pain in patients with chronic plantar fasciitis refractory to appropriate conservative management. $^{25}$

Furthermore, Martinez et al, in a recent search of electronical database, noted there are also little data about PRP safety. They also observed several methodologic limitations and, consequently, future research should focus on strong and well-designed RCTs that assess the efficacy and safety of PRP. ${ }^{26}$

Moreover studies are currently under way to clarify some of the questions that still remain unanswered regarding the long-term durability of these procedures and the possible modifications that can still be done to achieve better results.

Bio-technology is progressing at a rapid pace, exploring new horizons and allowing the introduction of numerous products for clinical application. However, carefully conducted randomised prospective studies for each of these innovations should be carried out to validate the safety and efficacy.

\section{CONCLUSION}

PRP in plantar fasciitis shows promising short term results providing patients with gradual sustained pain relief, improving daily function and lifestyle activity level. However we suggest that standardization is required in terms of system of production of platelet rich plasma and its characteristics, therapeutic indications, technique of administration and therapeutic dosage.

\section{ACKNOWLEDGEMENTS}

I would like thank my head of department, my guide, faculty members, colleagues for their constant support and helping hands in making the study successful.

I also like to thanks blood bank faculty, staff for their support in making the qualitative PRP showing beneficial effects to the patients.

\section{Funding: No funding sources} Conflict of interest: None declared

Ethical approval: The study was approved by the institutional ethics committee 


\section{REFERENCES}

1. Marx RE. Platelet-rich plasma (PRP): what is PRP and what is not PRP? Implant Dent. 2001;10(4):225-8.

2. Mazzucco L, Balbo V, Cattana E, Borzini P. Platelet-rich plasma and platelet gel preparation using Plateltex. Vox Sang. 2008;94(3):202-8.

3. Bennett NT, Schultz GS. Growth factors and wound healing: biochemical properties of growth factors and their receptors. Am J Surg. 1993;165(6):728-37.

4. Eppley BL, Woodell JE, Higgins J. Platelet quantification and growth factor analysis from platelet-rich plasma: implications for wound healing. Plast Reconstr Surg. 2004;114(6):1502-8.

5. Weibrich G, Hansen T, Kleis W, Buch R, Hitzler WE. Effect of platelet concentration in platelet-rich plasma on peri-implant bone regeneration. Bone. 2004 Apr;34(4):665-71.

6. Marlovits S, Mousavi M, Gabler C, Erdös J, Vécsei V. A new simplified technique for producing platelet-rich plasma: A short technical note. Eur Spine J. 2004;13:102-6.

7. Carofino B, Chowaniec DM, McCarthy MB, Bradley JP, Delaronde S, Beitzel $\mathrm{K}$, et al. Corticosteroids and local anesthetics decrease positive effects of platelet-rich plasma: an in vitro study on human tendon cells. Arthroscopy. 2012;28(5):711-9.

8. Pfeffer G, Bacchetti P, Deland J, Lewis A, Anderson R, Davis W, et al. Comparison of custom and prefabricated orthoses in the initial treatment of proximal plantar fasciitis. Foot Ankle Int. 1999;20:214-21.

9. Cole C, Seto C, Gazewood J. Plantar fasciitis: evidence-based review of diagnosis and therapy. Am Fam Physician. 2005;72:2237-42.

10. Taunton J, Ryan M, Clement D, McKenzie D, Lloyd-Smith D, Zumbo B. A retrospective casecontrol analysis of 2002 running injuries. $\mathrm{Br}$ J Sports Med. 2002;36:95-101.

11. Buchbinder R. Clinical practice. Plantar fasciitis. N Engl J Med. 2004;350:2159-2166

12. Crawford F, Thomson C. Interventions for treating plantar heel pain (Review). Cochrane. 2003.

13. Wolgin M, Cook C, Graham C, Mauldin D. Conservative treatment of plantar heel pain: longterm follow-up. Foot Ankle Int. 1994;15:97-102.

14. Davies M, Weiss G, Saxby T. Plantar fasciitis: how successful is surgical intervention? Foot Ankle Int. 1999;20:803-7.
15. Acevedo J, Beskin J. Complications of plantar fascia rupture associated with corticosteroid injection. Foot Ankle Int. 1998;19:91-7.

16. Sellman J. Plantar fascia rupture associated with corticosteroid injection. Foot Ankle Int. 1994;15:376-81.

17. Leach R, Jones R, Silva T. Rupture of the plantar fascia in athletes. $J$ Bone Joint Surg [Am]. 1978;60:537-9.

18. Nirschl R. Elbow tendinosis/tennis elbow. Clin Sports Med. 1992;11:851-70.

19. Scott J, Huskisson EC. Vertical or horizontal visual analogue scales. Ann Rheum Dis. 1979;38:560.

20. Monto RR. Platelet-rich plasma efficacy versus corticosteroid injection treatment for chronic severe plantar fasciitis. Foot Ankle Int. 2014;35:313-8.

21. Martinelli N, Marinozzi A, Carnì S, Trovato U, Bianchi A, Denaro V. Platelet-rich plasma injections for chronic plantar fasciitis. Int Orthop. 2013;37:839-42.

22. Peerbooms JC, van Laar W, Faber F, Schuller HM, van der Hoeven $\mathrm{H}$, Gosens T. Use of platelet rich plasma to treat plantar fasciitis: design of a multicentre randomized controlled trial. BMC Musculoskelet Disord. 2010;11:69.

23. Baravarian B, Chandler LM, De Heer P. PointCounterpoint: Is PRP Beneficial For Chronic Plantar Fasciitis? Podiatry today, 2013. Available at http://www.podiatrytoday.com/point-counterpointprp-beneficial-chronic-plantar-fasciitis. Accessed on 10 January 2017.

24. Kumar V, Millar T, Murphy PN, Clough T. The treatment of intractable planter fasciitis with platelet-rich plasma injection. Foot (Edinb). 2013;23:74-7.

25. Wilson JJ, Lee KS, Miller AT, Wang S. Platelet-rich plasma for the treatment of chronic planter fasciopathy in adults: a case series. Foot Ankle Spec. 2014;7:61-7.

26. Martinelli N, Marinozzi A, Carnì S, Trovato U, Bianchi A, Denaro V. Platelet-rich plasma injections for chronic plantar fasciitis. Int Orthop. 2013;37:839-42.

Cite this article as: Kadam R, Vijay S, Chhallani A, Pandhare S, Gupta A, Singh RS. Efficacy of platelet rich plasma injection in treatment of plantar fasciitis. Int J Res Orthop 2017;3:451-5. 